\title{
LA DOCTRINA DEL TJUE SOBRE LA TRIBUTACIÓN EN EL IVA DE LOS PREMIOS OBTENIDOS EN COMPETICIONES DEPORTIVAS
}

\author{
ESTEFANÍA LÓPEZ LLOPIS'
}

estefania.lopez@ua.es

\author{
Cómo citar/Citation \\ López Llopis, E. (2017) \\ La doctrina del TJUE sobre la tributación en el IVA \\ de los premios obtenidos en competiciones deportivas. \\ Revista de Derecho Comunitario Europeo, 58, 1007-1038. \\ doi: https://doi.org/10-18042/cepc/rdce.58.06
}

\section{Resumen}

La opinión mantenida por el Tribunal de Justicia de la Unión Europea (TJUE) en la reciente sentencia Baštová, C-432/15, echa por tierra el criterio tradicionalmente sostenido por los tribunales españoles y la Dirección General de Tributos (DGT) acerca de la sujeción al IVA de los premios obtenidos en competiciones deportivas. Mientras estos últimos consideran que una prestación de servicios cuya retribución se materializa en un premio constituye una operación sujeta a IVA, dos argumentos conducen a aquel a decantarse por la conclusión contraria: la inexistencia de una relación directa entre el servicio prestado y la retribución obtenida por el sujeto pasivo y el carácter incierto de dicha retribución. La principal conclusión que obtenemos es que, en los últimos años, la jurisprudencia y la doctrina administrativa española se han apartado sistemáticamente de la jurisprudencia comunitaria en relación con los elementos que debe reunir una prestación de servicios para considerarse realizada a título oneroso y, por tanto, quedar sujeta al impuesto.

\section{Palabras clave}

Impuesto sobre el Valor Añadido, prestación de servicios, título oneroso, contraprestación, premios.

1 Profesora ayudante doctora de la Universidad de Alicante. 


\title{
THE ECJ JURISPRUDENCE ON VAT TAXATION OF PRIZES OBTAINED IN A SPORTS COMPETITION
}

\begin{abstract}
The decision adopted by the European Court of Justice (ECJ) in Baštová (Case C-432/15) invalidates the criteria traditionally supported by national judges and the Spanish DGT about indirect taxation of prizes obtained in a sports competition. Whereas these entities consider that a supply of services is subject to VAT even when it is compensated with prize money, the ECJ employs two different arguments to support the opposite conclusion. On the one hand, the absence of a direct relation between the service and the compensation received by the taxable person. On the other, the uncertainty about the existence of that compensation. We conclude that, in the last years, judicial and administrative authorities have systematically got away from the ECJ's decisions in relation to the requirements that must be fulfilled in order to consider that a supply of services has been effected for consideration and, therefore, is subject to VAT.
\end{abstract}

\section{Keywords}

Value-Added Tax, supply of services, for consideration, compensation, prize money.

\section{LA DOCTRINE DE LA COUR DE JUSTICE DE L'UNION EUROPÉENNE SUR L'ASSUJETTISSEMENT À LA TVA DES PRIX OBTENUS DANS DES COMPÉTITIONS SPORTIVES}

\section{Résumée}

La Cour de justice de l’Union européenne dans la récente sentence Baštová, C-432/15, abandonne le critère traditionnellement soutenu par les tribunaux espagnols et la Direction Générale de Taxation concernant l'assujettissement à la TVA des prix obtenus dans de compétitions sportives. En tant que ceux derniers considèrent qu'une prestation de services, dont la rétribution est matérialisée dans un prix, constitue une opération assujettie à la TVA, deux arguments amènent à celui-là à se pencher pour la conclusion contraire : l'inexistence d'une relation directe entre le service fourni et la rétribution obtenue par l'assujettie et le caractère incertain de ladite rétribution. La principale conclusion obtenue est que, dans les dernières années, la jurisprudence et la doctrine administrative espagnoles ont été éloignées systématiquement de la jurisprudence communautaire concernant les éléments qui doit réunir une prestation de services pour pouvoir être considérée comme réalisée à titre onéreux et, conséquemment, étant assujettie à la TVA.

\section{Mots clés}

Taxe sur la valeur ajoutée, prestation de services, titre onéreux, contreprestation, prix. 


\section{SUMARIO}

I. INTRODUCCIÓN. II. LA DOCTRINA DEL VÍNCULO DIRECTO: 1. La existencia de una relación jurídica de intercambio. 2. El carácter determinado de la contraprestación pactada. 3. El principio de subjetividad de la contraprestación. 4. La existencia de un consumo y de un consumidor identificable. III. LA DOCTRINA DEL TJUE EN LA SENTENCIA BAŠTOVÁ. IV. CONEXIÓN DE LA SENTENCIA BAŠTOVÁ CON EL DERECHO ESPAÑOL: 1. La doctrina de la Dirección General de Tributos (DGT). 2. La doctrina de los tribunales españoles. V. ANÁLISIS DE LA SENTENCIA BAŠTOVÁ A LA LUZ DE LA JURISPRUDENCIA COMUNITARIA. VI. LA TESIS DEL ABOGADO GENERAL EN EL ASUNTO BAŠTOVÁ. COMENTARIO CRÍTICO. VII. CONCLUSIONES.

\section{INTRODUCCIÓN}

La Sentencia del Tribunal de Justicia Baštová, C-432/15, EU:C:2016:855, analiza una serie de cuestiones relativas a la tributación en el IVA de los premios obtenidos en una competición deportiva. Concretamente, la sentencia plantea el caso de la Sra. Baštová, inscrita como sujeto pasivo a efectos del IVA en la República Checa y dedicada al desarrollo de una actividad económica consistente en la explotación de una instalación hípica para caballos de carreras. En dicha instalación, la Sra. Baštová cría y entrena caballos, tanto propios como de terceros, con vistas a su participación en carreras. Además, dispone de dos caballos destinados a actividades de agroturismo y de entrenamiento de caballos jóvenes y de varias yeguas de cría y potros destinados a la venta.

La Sra. Baštová obtiene dos tipos de ingresos como consecuencia de su actividad: por un lado, ingresos procedentes de los premios obtenidos por sus caballos y por los caballos de terceros que participan en carreras, de los que se queda un porcentaje en calidad de entrenadora, y, por otro, ingresos derivados de los pagos percibidos por el servicio de entrenamiento de caballos que presta a terceros.

En su declaración de IVA correspondiente al último trimestre del año 2010, la Sra. Baštová se dedujo íntegramente las cuotas soportadas en la compra de bienes y de servicios destinados a la preparación, manutención y cuidado, tanto de sus caballos como de los caballos de terceros. La Oficina 
Tributaria de Ostrov (República Checa) negó el derecho a toda deducción, al entender que una parte de los bienes y servicios adquiridos habían sido empleados para la realización de operaciones que no originan el derecho a deducir, como es la participación en carreras de caballos. La Sra. Baštová presentó un recurso contra esta resolución ante la Dirección Tributaria de Pilsen, que únicamente denegó la deducción de la parte del IVA soportado por la misma en la compra de bienes y servicios destinados a la preparación, manutención y cuidado de sus propios caballos.

La Sra. Baštová recurrió esta última resolución ante el Tribunal Regional de Pilsen, que, después de estimar el asunto, lo remitió a la Dirección Tributaria Competente en Materia de Recursos de la República Checa. Después de interponer recurso de casación contra el Tribunal Supremo de lo Contencioso-administrativo de la República Checa, este último órgano decidió suspender el procedimiento y plantear una serie de cuestiones prejudiciales al Tribunal de Justicia de la Unión Europea (TJUE). Entre ellas, el órgano jurisdiccional remitente pide que se dilucide si la puesta a disposición de un caballo a favor del organizador de una carrera hípica con vistas a su participación en la misma constituye una operación sujeta al IVA. En particular, lo que suscita dudas al juez nacional radica en la existencia de una contraprestación que atribuya carácter oneroso a la referida prestación de servicios y que, en su opinión, podría venir determinada por la oportunidad misma de participar en la carrera o por el premio eventualmente percibido por el propietario del caballo en atención a su clasificación.

Según la descripción de los hechos, la participación de un caballo en la carrera está supeditada al pago de unos derechos de inscripción y participación. Por tanto, sostiene el TJUE, cuando el organizador del evento confiere al propietario del caballo la posibilidad de participar en el mismo previo pago de la cuota correspondiente, lo que tiene lugar es una prestación de servicios autónoma e independiente entre el organizador de la carrera hípica, que actúa como prestador del servicio, y el propietario del caballo, que recibe el servicio a cambio de una contraprestación ${ }^{2}$. Las dudas que verdaderamente se plantean guardan relación con una hipotética prestación de servicios a título oneroso entre el propietario del caballo, que prestaría dicho servicio al poner su caballo a disposición del organizador de la carrera, y el propio organizador de la carrera, que actuaría como destinatario del mismo.

Por lo que se refiere a esta última cuestión, debemos tener en cuenta que la Sra. Baštová no percibe una remuneración fija con motivo de su participa-

2 Acerca de esta prestación de servicios, véanse las Conclusiones del abogado general Wahl en el asunto Baštová, C-432/15, EU:C:2016:438, puntos 32 a 34. 
ción en carreras hípicas, aunque sí opta, en igualdad de condiciones con respecto al resto de participantes, a la obtención de un premio en función de la clasificación obtenida por su caballo. De acuerdo con esta premisa, la primera tarea del TJUE radica en determinar si el premio eventualmente percibido por el propietario del caballo tiene naturaleza de contraprestación de una prestación de servicios, ya que, solo en tal caso, la puesta a disposición del animal a favor del organizador de la carrera constituiría una operación sujeta al IVA.

El objetivo de este trabajo consiste en acometer un análisis del razonamiento esgrimido por el Tribunal de Justicia para fundamentar su decisión final, en virtud de la cual la operación realizada por el propietario del caballo no reúne los requisitos necesarios para ser considerada una prestación de servicios a título oneroso. Dicho análisis se complementará, en primer lugar, con un estudio de la literatura existente en torno a la llamada doctrina del vínculo directo, en la que se inserta la cuestión debatida en este asunto. En segunda instancia, efectuaremos una revisión de los criterios tradicionalmente defendidos por la Administración tributaria y por los tribunales españoles para sustentar la sujeción al IVA de los premios obtenidos en una competición deportiva. El trabajo culminará con un comentario crítico sobre los argumentos empleados por el abogado general en el asunto objeto de examen para apartarse de las conclusiones del tribunal europeo.

\section{LA DOCTRINA DEL VÍNCULO DIRECTO}

En el asunto Baštová, el Tribunal de Justicia invoca una vez más la llamada doctrina del vínculo directo, formulada por vez primera en la sentencia de 5 de febrero de 1981, Coöperatieve Aardappelenbewaarplaats, C-154/80, EU:C:1981:38, y fruto de una prolija y extensa jurisprudencia comunitaria. En esta ocasión, no obstante, la doctrina del vínculo directo es abordada por el tribunal desde un prisma a mi juicio novedoso, hasta ahora no planteado ni en el ámbito jurisprudencial ni en el contexto de la doctrina científica. De aquí la relevancia que la sentencia Baštová está llamada a adquirir en el campo de la fiscalidad indirecta.

En su formulación inicial, la doctrina del vínculo directo reclama la existencia de una relación directa entre el bien que se entrega o el servicio que se presta y la contraprestación que se recibe a cambio como requisito sine qua non para que dicha transacción caiga dentro del ámbito de aplicación del IVA. Como acertadamente señalan Granizo Labrandero y Pérez Cantero, se trata de una doctrina que surge para «determinar el carácter oneroso de una 
operación y saber si efectivamente esa operación implica el gravamen por el impuesto» ${ }^{3}$.

La complejidad asociada a los supuestos que sucesivamente se han planteado al TJUE, y que han sido resueltos a la luz de esta doctrina, han exigido una labor de concreción y especificación del «vínculo directo» y de los requisitos que necesariamente deben concurrir para que pueda apreciarse su existencia y el consiguiente carácter oneroso de la transacción realizada. A continuación analizaremos los distintos elementos sobre los que se ha sustentado esta doctrina hasta la sentencia Baštová.

\section{LA EXISTENCIA DE UNA RELACIÓN JURÍDICA DE INTERCAMBIO}

En los términos señalados por Sánchez Sánchez, la doctrina del vínculo directo se materializa en el cumplimiento de dos requisitos ${ }^{4}$. De un lado, se precisa la existencia de una «relación biunívoca» o "contrato sinalagmático» del que deriven derechos y obligaciones para las dos partes intervinientes en la operación. De otro, es necesario que la retribución efectivamente percibida por quien efectúa la prestación se configure como «contravalor efectivo» del servicio prestado al destinatario.

En relación con el primero de los requisitos mencionados, sostiene González-Cuellar Serrano que una determinada remuneración solo puede encajar en el concepto de contraprestación a los efectos del IVA cuando constituya la «contrapartida efectiva de un servicio individualizado prestado en el marco de una relación jurídica en la que se intercambian prestaciones recíprocas $»^{5}$. Esta reciprocidad entre las prestaciones realizadas y recibidas es la que dota de un carácter sinalagmático a la relación jurídica o contractual exigida entre las partes a la luz de la doctrina del vínculo directo.

3 José Javier GRANIZO LABRANDERO y Esther PÉREZ CANTERO, «El hecho imponible en el Impuesto sobre el Valor Añadido. Operaciones interiores. Concepto de empresario y profesional. Las entregas de bienes y las prestaciones de servicio», en José Manuel DE BUNES IBARRA (dir.), Manual sobre el Impuesto sobre el Valor Añadido,,Instituto de Estudios Fiscales, Madrid, 2008, pp. 113-164, 118-119.

4 Ángel SÁNCHEZ SÁNCHEZ, «La inclusión de las subvenciones en la base imponible del IVA de acuerdo a la jurisprudencia del TJCE», Revista Técnica Tributaria, núm. 79, 2007, pp. 97-116, p. 102.

5 Ma Luisa GONZÁLEZ-CUELLAR SERRANO, «Arras entregadas en el marco de contratos relativos a prestaciones de servicios sujetas a IVA y que quedan en poder de quien efectúa la prestación en caso de desistimiento (STJCE de 18 de julio de 2007, As. C-277/05)», Noticias de la Unión Europea, núm. 302, 2010, pp. 99-101, p. 100. 
A efectos de valorar la concurrencia de la citada relación jurídica, propone Sánchez Gallardo un enfoque ciertamente novedoso, consistente en «que la operación se plantee de tal forma que prestación y contraprestación estén vinculadas de forma tal que la falta de una implique también la falta de la otra ${ }^{6}$. Concretamente, dispone el referido autor que en el caso «de operaciones o situaciones complejas la existencia de una contraprestación ha de determinarse haciendo una comparación de la situación con la que existiría si no se realizase la operación para la cual se discute la existencia de una contraprestación. Si para el caso de que falte la operación, también desaparece la hipotética contraprestación, parece que sí que existe la relación directa o sinalagmática de la que venimos tratando» ${ }^{7}$. Es este criterio, de hecho, el que, según la tesis de González-Cuellar Serrano, determinaría la imposibilidad de conferir naturaleza de contraprestación a las llamadas arras penales y penitenciales, puesto que, con independencia de que las partes pacten o no el pago de las mismas, rige la obligación del empresario de no contratar con un tercero ${ }^{8}$.

A mi parecer, el criterio propuesto por Sánchez Gallardo resulta de especial interés en el marco de la sentencia Baštová, donde se discute la posibilidad de conferir al premio eventualmente percibido por el propietario del caballo ganador naturaleza de contraprestación por una prestación de servicios. Aunque la propuesta del citado autor gira en torno a una comparación entre la situación existente y la situación que existiría si no se efectuase la operación, las particularidades asociadas al asunto Baštová exigen llevar a cabo la comparación opuesta con la finalidad de determinar si la "prestación» recibida por el organizador del evento subsistiría en caso de que no se entregara la «contraprestación» pactada (el premio). La conclusión a la que llegamos a partir de dicha comparación es clara: el servicio hipotéticamente prestado al organizador de la carrera por cualquiera de los participantes (que consiste,

6 Francisco Javier SÁNCHEZ GALLARDO, «La sentencia de 22 de noviembre de 2001 del Tribunal de Justicia de las Comunidades Europeas, la inclusión de las subvenciones en la base imponible del IVA», Carta Tributaria, núm. 6, 2002, pp. 1-35, p. 23. Este mismo enfoque se propone también en el trabajo de Antonio MARTÍNEZ LAFUENTE, «La actividad económica ante el Sistema Tributario. Especial referencia a la actividad urbanizadora", Impuestos: Revista de doctrina, legislación y jurisprudencia, año núm. 25, núm. 8, 2009, pp. 11-46.

7 SÁNCHEZ GALLARDO, op. cit., nota 5, p. 24.

8 GONZÁLEZ-CUELLAR SERRANO, loc. cit., nota 4. Una clasificación de las distintas tipologías de arras existentes y del tratamiento que deben recibir en el ámbito del IVA puede encontrarse en Andrea GARCÍA CASTELAO, "Las arras en el Impuesto sobre el Valor Añadido español: impacto de la STJCE de 18 de julio de 2007», Jurisprudencia Tributaria Aranzadi, núm. 13, 2007, pp. 9-12. 
precisamente, en su participación en dicho evento) existirá aun cuando no pueda accederse al premio acordado por no haber alcanzado la posición que a tal fin resultaba necesaria. Esta circunstancia determina la ruptura del vínculo directo que debe existir entre prestación y contraprestación para que la operación realizada pueda considerarse sujeta al IVA.

La conclusión anterior se refuerza si efectuamos una equiparación entre los premios obtenidos en el marco de una competición deportiva y las arras entregadas por un cliente que quedan en poder del empresario que presta el servicio en el supuesto de que aquel haga uso de la facultad de desistimiento que le asiste (arras de naturaleza indemnizatoria). Tal y como señala González-Cuellar Serrano, las arras «no tienen relación directa con ningún servicio prestado a título oneroso», o, lo que es lo mismo, no constituyen «la retribución de ninguna prestación»" ${ }^{9}$. De igual modo sucede con los premios, cuyo pago no puede conectarse, al menos desde mi punto de vista, a ningún servicio concreto prestado por el participante que resulta ganador, lo que supone la ruptura del vínculo directo y, por consiguiente, la imposibilidad de apreciar la existencia de una operación realizada a título oneroso.

La posible calificación de la contraprestación recibida por el prestador del servicio como «contravalor efectivo» del servicio prestado, por otro lado, parece hacerse depender de la existencia de un «vínculo necesario» entre la prestación que se realiza y la contraprestación que se recibe a cambio. Tal vínculo necesario no puede apreciarse, de acuerdo con la doctrina científica, cuando la supuesta contraprestación no se determine o cuantifique en función de la prestación recibida.

A fin de arrojar algo de luz sobre los criterios a tener en cuenta para valorar la concurrencia del requisito señalado, apunta Sánchez Gallardo que la relación existente entre prestación y contraprestación debe ser tal «que, entre la magnitud del beneficio que le reporta al destinatario de dicho servicio y la cuantía de la contraprestación pueda establecerse una conexión» ${ }^{10}$. Dicho en otras palabras, «la relación directa entre prestación y contraprestación implica que ha de existir algún tipo de relación o proporción matemática entre prestación y contraprestación, de manera que una mayor prestación sólo se haga efectiva si se obtiene a cambio una mayor contraprestación ${ }^{11}$. El aclamado vínculo necesario no existiría, por tanto, cuando no sea posible graduar la cantidad de servicios prestados en función de la retribución percibida o cuando

\footnotetext{
9 GONZÁLEZ-CUELLAR SERRANO, loc. cit., nota 4.

10 SÁNCHEZ GALLARDO, op. cit., nota 5, p. 13.

11 SÁNCHEZ GALLARDO, loc. cit., nota 5.
} 
los servicios sean prestados con total independencia de la remuneración que por ello se reciba.

Altamente ilustrativo en este contexto resulta el ejemplo propuesto por Lang et al. para fundamentar la noción de "contravalor efectivo». En concreto, señalan los autores, si una determinada agencia destina cuatro horas a atender al sujeto A y cuatro horas a atender al sujeto $B$, pero al sujeto A se le permite pagar mucho menos por el servicio recibido como consecuencia de sus reducidos ingresos, no se aprecia la existencia de un vínculo directo entre prestación y contraprestación ${ }^{12}$. Sobre la base de este razonamiento, concluyen los autores que el vínculo directo se quiebra cuando la remuneración satisfecha por el destinatario no emana de la prestación recibida. Tal situación se produce cuando el importe de dicha remuneración se hace depender de factores externos (es decir, de circunstancias no relacionadas con el servicio prestado), y no de la calidad o el volumen de la prestación recibida.

A modo de corolario de las tesis anteriores, concluye Rodríguez Márquez que la sujeción al impuesto se cifra «en la existencia de un contravalor, que es siempre imprescindible y debe constituir la retribución exacta del servicio. Así pues, para que pueda hablarse de una prestación de servicios en el sentido de la normativa comunitaria, ha de existir un beneficio y una retribución, que debe ser de carácter contractual. Además, estos elementos deben estar unidos mediante una relación directa, de modo que el precio refleje exactamente las ventajas proporcionadas por el servicio. De ahí la utilización del término «contravalor» en lugar de otro cualquiera que pudiera expresar una idea semejante» ${ }^{13}$.

\section{EL CARÁCTER DETERMINADO DE LA CONTRAPRESTACIÓN PACTADA}

A esta exigencia hace referencia Sánchez Gallardo cuando indica que «una prestación de servicios para la cual no se ha determinado ni percibido ninguna contraprestación subjetiva no es una prestación de servicios efectua-

12 Michael LANG et al., CJEU-Recent Developments in Value Added Tax 2016, Series on International Tax Law, Vol. 105, Linde Verlag, Wien, 2017, p. 241. En este mismo sentido se pronuncia Anisuka DUARDO SÁNCHEZ, "El término 'contravalor' y la definición de 'actividad económica' a efectos del IVA. STJCE de 29 de octubre de 209 (As. C-246/08), Comisión v. República de Finlandia», Noticias de la Unión Europea, núm. 318, 2011, pp. 51-55, p. 54.

13 Jesús RODRÍGUEZ MÁRQUEZ, «La polémica en torno a la sujeción a IVA de la participación de los clubes en las quinielas», Revista Aranzadi de Derecho de Deporte y Entretenimiento, núm. 24, 2008, pp. 349-358, p. 351. 
da a título oneroso y, por tanto, no está sujeta al IVA» ${ }^{14}$. Desde este punto de vista, se refiere el autor a la «indeterminación de la base imponible de una operación concreta» como elemento decisivo para negar su carácter oneroso.

Dando un paso más, De Juan Casadevall alude al requisito de «determinabilidad» (que no determinación) de la contraprestación acordada entre las partes al analizar la evolución de la doctrina del vínculo directo y su incidencia en el ámbito de las subvenciones. En este contexto, sostiene el citado autor, para que una subvención entre dentro del concepto de contraprestación, y, en consecuencia, deba formar parte de la base imponible del IVA, es necesaria la «identificación y determinabilidad de la contraprestación» ${ }^{15}$. De conformidad con este razonamiento, el hecho de que la contraprestación pactada no sea determinada no implica necesariamente una ruptura del vínculo directo, siendo suficiente que la misma sea determinable. Tal aproximación a la doctrina del vínculo directo resulta compatible con la propia jurisprudencia del Tribunal europeo, que en algunas ocasiones ha reconocido la posibilidad de que la cuantía de la retribución inicialmente acordada sea objeto de modificación posterior a la prestación del servicio de que se trate en función de las circunstancias concurrentes.

\section{EL PRINCIPIO DE SUBJETIVIDAD DE LA CONTRAPRESTACIÓN}

Este principio se concreta en la necesidad de que la base imponible del IVA venga constituida por la contrapartida realmente percibida por quien realiza la prestación y no por un valor estimado según criterios objetivos. Así se pronuncia Sánchez Gallardo cuando sostiene que «La evaluación de la contraprestación ha de realizarse sobre una base subjetiva, no siendo factible la utilización de métodos objetivos más que cuando así esté específicamente previsto» ${ }^{16}$. En esta misma línea, defiende García Balseiro, haciendo alusión a la jurisprudencia comunitaria, que la base imponible en el IVA está constituida por la contraprestación entendida como valor subjetivo, es decir, por el valor realmente percibido en cada caso concreto. «Por tanto, la subjetividad es inherente a la base imponible, rechazando cualquier intento de objetivación» ${ }^{17}$.

14 SÁNCHEZ GALLARDO, op. cit., nota 5, p. 2.

15 Jorge DE JUAN CASADEVALL, «La recuperación administrativa del IVA de subvenciones regularizado a concesionarios de servicios públicos: FACTUM PRINCIPIS Y REBUS SIC STANTIBUS», Quincena Fiscal, núm. 14, 2017, pp. 23-38, p. 27.

16 SÁNCHEZ GALLARDO, op. cit., nota 5, p. 24.

17 Gema GARCÍA BALSEIRO, «IVA: base imponible, la contraprestación representada por bonos. Comentario a la jurisprudencia del Tribunal de Justicia de la Comunidad 
A priori, el principio de subjetividad podría plantear ciertas dudas en cuanto a su relevancia en el ámbito de la doctrina del vínculo directo. A juicio de Sánchez Sánchez, no obstante, este principio de subjetividad complementa y refuerza el principio de relación directa inicialmente formulado por el Tribunal de Justicia. En este sentido, argumenta el citado autor, «de la exigencia de una relación biunívoca, de un quid pro quo entre prestación y contraprestación para que exista sujeción al IVA, se desprende la necesidad de que el importe de la base imponible sea la contraprestación efectivamente recibida, de su valor subjetivo y específico en esa operación, y no de un valor estimado de manera objetiva ${ }^{18}$.

Ahondando un poco más en la cuestión, analiza Gómez Aragón la aplicabilidad de este requisito en el supuesto de que la contraprestación pactada entre las partes fuera no dineraria. De ser este el caso, distingue el autor dos opciones, según que las partes hayan atribuido a la contraprestación un valor dinerario o no. Cuando resultase acreditado que las partes hubiesen atribuido de forma directa y expresa un valor dinerario a la contraprestación acordada, «tal valor dinerario es el que debería tenerse en cuenta como valor subjetivo que se corresponde con lo realmente percibido por la empresa que realiza la operación (...). En ausencia de la referida atribución directa y expresa de un valor dinerario a la contraprestación no dineraria, tal valor habrá de determinarse de manera indirecta en cada caso concreto, pero en ningún caso recurriendo para ello a criterios abstractos u objetivos (...), sino atendiendo a criterios subjetivos que pongan de manifiesto cuál es el valor realmente atribuido a la contraprestación no dineraria por la empresa que la percibe como contravalor de la operación cuya base imponible se trata de determinar» ${ }^{19}$.

\section{LA EXISTENCIA DE UN CONSUMO Y DE UN CONSUMIDOR IDENTIFICABLE}

A esta condición se refiere Sánchez Gallardo cuando, al analizar la jurisprudencia del Tribunal europeo, afirma que el vínculo necesario entre prestación y contraprestación se quiebra cuando el servicio prestado redunda de manera general en beneficio de todo un sector y no de un sujeto individualmente

Europea de 24 de octubre de 1996», Impuestos: Revista de doctrina, legislación y jurisprudencia, año núm. 13, núm. 2, 1997, pp. 1104-1113, p. 1107.

18 SÁNCHEZ SÁNCHEZ. op. cit., nota 3, p. 103.

19 David GÓMEZ ARAGÓN, «Base imponible del IVA en operaciones con contraprestación no dineraria», Carta Tributaria, núm. 3, 2015, pp. 15-33, p. 32. 
considerado ${ }^{20}$. De aquí su alusión a la «identificación o identificabilidad de los hipotéticos clientes» como otro de los criterios relevantes a la hora de valorar la sujeción al IVA de una determinada operación ${ }^{21}$.

De especial interés en este punto resulta la referencia efectuada por el propio Sánchez Gallardo a la sentencia Tolsma, en la que con mayor contundencia asienta el Tribunal de Justicia la doctrina del vínculo directo ${ }^{22}$. Concretamente, alude el autor a la imposibilidad material de proceder a la identificación de los destinatarios de la operación como uno de los factores determinantes de la decisión del Tribunal en este asunto, donde se niega la sujeción al IVA de las prestaciones controvertidas. "Corolario de lo anterior es la inexistencia de un beneficio o utilidad reportada a alguien, ello en la línea (...) de considerar el IVA como un impuesto sobre el consumo» ${ }^{23}$. De acuerdo con este razonamiento, la imposibilidad de identificar a los hipotéticos destinatarios de la operación y, «derivada de ello, la imposibilidad de apreciar un consumo de servicios, siquiera sea como mera puesta a disposición de los mismos», conducen ineludiblemente a la exclusión de una determinada operación del ámbito de aplicación del IVA.

El requisito relativo a la existencia de un consumo y de un consumidor identificable también ha sido abordado por Rodríguez Márquez, quien advierte que "para la concurrencia del hecho imponible del tributo, es necesario que pueda identificarse un consumo proporcionado a una persona o grupo de personas identificable» ${ }^{24}$. Tal circunstancia se cumple cuando el servicio prestado sea necesario para el desarrollo de una determinada actividad empresarial, en el sentido de que constituya un input de otro empresario o profesional o un coste asociado a la actividad de otra persona que participa en la cadena comercial $^{25}$.

Por lo que se refiere al lugar que esta exigencia ocupa en el ámbito de la doctrina del vínculo directo, el profesor Sánchez Sánchez ha afirmado en alguna ocasión que el requisito de que exista un consumo y un consumidor identificable no debe ser entendido como parte de la citada doctrina, sino como complemento de la misma. A su entender, los pronunciamientos emiti-

20 SÁNCHEZ GALLARDO, op. cit., nota 5, p. 22.

21 SÁNCHEZ GALLARDO, op. cit., nota 5, pp. 14 y 17.

22 Sentencia Tolsma, C-16/93, EU:C:1994:80, apdos. 13 y 14. En este sentido se pronuncia SÁNCHEZ SÁNCHEZ, op. cit., nota 3, p. 101.

23 SÁNCHEZ GALLARDO, op. cit., nota 5, p. 14.

24 RODRÍGUEZ MÁRQUEZ, op. cit., nota 12, p. 352.

25 En un sentido similar, véase Francisco Javier SÁNCHEZ GALLARDO, «Tratamiento de las subvenciones en el Impuesto sobre el Valor Añadido», Carta Tributaria, núm. 10, 2001, pp. 1-28, p. 15. 
dos por el TJUE en este contexto permiten afirmar que dicho órgano «da un paso más, al establecer que no basta con que exista un vínculo directo entre prestación y contraprestación para que una transacción se someta a tributación en el IVA. Es necesario, además, que la misma se destine al consumo de un bien o servicio por parte de un consumidor identificable» ${ }^{26}$.

\section{LA DOCTRINA DEL TJUE EN LA SENTENCIA BAŠTOVÁ}

En los términos antes señalados, la sentencia Baštová supone un importante avance en el proceso de formulación de la doctrina del vínculo directo, ya que aborda dicha doctrina desde un prisma novedoso. La novedad del enfoque adoptado radica en el hecho de que, por vez primera, el Tribunal de Justicia hace depender su decisión final de un elemento ya avanzado en la sentencia Tolsma pero en modo alguno determinante de la conclusión alcanzada en el marco de dicho asunto: la certeza en cuanto a la existencia misma de retribución, o, dicho en otras palabras, la ausencia de aleatoriedad en el precio o contraprestación pactada ${ }^{27}$. Desde este punto de vista, la sentencia Baštová no solo recuerda la doctrina del vínculo directo (pasando a formar parte del amplio elenco de sentencias europeas en las que se invoca esta doctrina), sino que, de hecho, lleva a cabo una extensión de la propia noción de «vínculo directo" y una especificación del requisito de certeza que la sentencia Tolsma mencionaba con una finalidad meramente auxiliar.

Centrándonos en el contenido de la sentencia Baštová, el razonamiento esgrimido por el Tribunal europeo para rechazar la sujeción al IVA del premio eventualmente percibido en el marco de una carrera hípica se sustenta, precisamente, en la doctrina del vínculo directo, esto es, en la inexistencia de una relación directa entre dicho premio y el servicio prestado por el propietario del caballo al organizador de la carrera ${ }^{28}$. En el supuesto de hecho

26 SÁNCHEZ SÁNCHEZ, op. cit., nota 3, p. 104.

27 Sentencia Tolsma, apdo. 19. Lo mismo sucede, respecto de este mismo criterio, en la sentencia del TJUE Cibo Participations, C-16/00, ECLI:EU:C:2001:495, apdos. 42 y 43, donde el carácter incierto en cuanto a la existencia misma de retribución es empleado como argumento adicional para negar la posibilidad de que un dividendo, cuyo importe depende de los resultados obtenidos por la sociedad en el ejercicio, pueda ser considerado como la contraprestación de una prestación de servicios.

28 Sentencia Baštová, apdo. 28. Asimismo, véanse las Sentencias del TJUE Coöperatieve Aardappelenbewaarplaats, antes citada, apdo. 12; Apple and Pear Development Council, 102/86, EU:C:1988:120, apdo. 12; Naturally Yours Cosmetics, 230/87, 
planteado, el cumplimiento de esta doctrina se concretaría en la existencia de una relación jurídica entre el propietario del caballo y el organizador de la carrera en virtud de la cual el primero de ellos se obligaría a poner su caballo a disposición del segundo a cambio de una contraprestación, mientras que el segundo se obligaría a satisfacer la contraprestación pactada al primero a cambio de la participación de su caballo en la carrera. Dado que la Sra. Baštová no obtiene ninguna retribución fija con motivo de su participación en la carrera hípica, determinar la sujeción al impuesto del servicio prestado por la misma pasa por analizar la naturaleza del premio que eventualmente puede percibir.

En primera instancia, resulta preciso esclarecer si el premio obtenido por el propietario del caballo que participa en la carrera retribuye realmente la puesta a disposición del caballo a favor del organizador del evento o, por el contrario, se trata de una remuneración justificada por una circunstancia distinta. La opinión del TJUE acerca de esta cuestión se encuentra claramente recogida en el apdo. 37 de la sentencia, en el que se afirma que «no es la puesta a disposición del caballo (...) la que, como tal, da derecho al pago de un premio, sino la obtención de un determinado resultado a la finalización de la carrera, esto es, la clasificación del caballo en un puesto determinado".

Por otro lado, debemos tener en cuenta que, conforme a la doctrina que puede extraerse de la sentencia Tolsma, la incertidumbre en cuanto a la existencia misma de retribución rompe el vínculo directo que necesariamente debe existir entre la prestación del servicio y la contraprestación recibida para que la operación realizada se encuentre sujeta al impuesto. Esta incertidumbre es consustancial a los premios como forma de retribución, de modo que está presente en el caso que ahora se analiza. Así, dado que los participantes en la carrera únicamente optan a la percepción de un premio con motivo de su participación en la misma y dicha percepción se hace depender de la clasificación finalmente obtenida por el caballo, la existencia de contraprestación resulta inicialmente desconocida para las partes. Este componente de aleatoriedad anula, a juicio del Tribunal, el carácter oneroso de la prestación de servicios, y ello con independencia de que el importe del premio haya sido fijado de antemano, de que dicho importe sea conocido por los eventuales ganadores y de que el organizador de la carrera se encuentre obligado al pago del mismo.

EU:C:1988:508, apdos. 11 y 12; Tolsma, antes citada, apdos. 13 y 14; Floridienne y Berginvest, C-142/99, EU:C:2000:623, apdo. 20; Campsa Estaciones de Servicio, C285/10, EU:C:2011:381, apdo. 25; Lebara, C-520/10, EU:C:2012:264, apdo. 27. 
Finalmente, recuerda el TJUE en el apdo. 38 de la sentencia Baštová que «el concepto de 'prestación de servicios' tiene carácter objetivo y se aplica con independencia de los fines y los resultados de las operaciones de que se trate ${ }^{29}$. En relación con esta doctrina, señalaba el abogado general Poiares Maduro, en el asunto Optigen y otros, C-354/03, EU:C:2005:89, apdo. 29, que el criterio de independencia con respecto a los fines y resultados perseguidos «se basa en la exigencia de que el sistema común del IVA debe ser neutral y en el principio de seguridad jurídica, que requiere que la aplicación de la normativa comunitaria sea previsible por quienes están sujetos a ella.» El principio de seguridad jurídica, por su parte, ha sido definido por el Tribunal europeo en diferentes sentencias. Tal es el caso de la Sentencia Dinamarca/Comisión, C-348/85, EU:C:1987:552, apdo. 19, donde dicho órgano dispone que «la legislación comunitaria debe ser precisa y su aplicación previsible para los justiciables. Este imperativo de seguridad jurídica (...) [debe] permitir que los interesados conozcan con exactitud el alcance de las obligaciones que se les imponen ${ }^{30}$.

Desde mi punto de vista, la traslación del criterio anterior al caso concreto de la Sra. Baštová justifica la necesidad de garantizar que, en el momento en el que el propietario de un caballo decide participar en una carrera hípica, es posible determinar si la prestación de servicios que el mismo va a realizar a favor del organizador de la carrera se encuentra sujeta o no sujeta al IVA. Si asumimos la premisa de que el premio percibido constituye la contraprestación por el servicio prestado, se dará la circunstancia de que solo aquellos propietarios que perciban un premio estarán obligados a repercutir el impuesto al organizador de la carrera. Por el contrario, los participantes que no resulten ganadores del premio, y, en consecuencia, no reciban ninguna contraprestación con motivo de su participación en el evento, no tendrán la consideración de prestadores de un servicio a efectos del IVA. De esta forma, considerar que el premio percibido constituye una contraprestación por el servicio prestado equivale a establecer un vínculo directo entre dicha prestación de servicios y el resultado alcanzado a través de la misma, lo que supone una vulneración del principio de seguridad jurídica y, por ende, del derecho comunitario en materia de imposición indirecta.

La consideración simultánea de los argumentos anteriores conduce a la conclusión de que, en un supuesto como el descrito, «en el que sólo los pro-

29 En el mismo sentido, véanse las Sentencias del TJUE Comisión/Reino Unido, C-359/97, EU:C:2000:426, apdo. 41; Optigen y otros, C-354/03, EU:C:2006:16, apdo. 43; Newey, C-653/11, EU:C:2013:409, apdo. 41.

30 En la misma línea, véanse las Sentencias del TJUE Reino Unido/Comisión, C-209/96, EU:C:1998:448, apdo. 35, y Sudholz, C-17/01, EU:C:2004:242, apdo. 34. 
pietarios de los caballos que obtengan una determinada clasificación al llegar a la meta obtienen un premio, no cabe considerar que la puesta a disposición del caballo dé lugar a una contrapartida efectiva» ${ }^{31}$. En la medida en que la ausencia de contraprestación anula el carácter oneroso de la operación, el servicio prestado por el propietario del caballo en estas condiciones no estará sujeto al impuesto. Así pues, el participante que resulte perceptor del premio no deberá repercutir el IVA al organizador de la carrera, independientemente de que el importe del premio haya sido determinado a priori y de que su pago sea obligatorio para el organizador en función de disposiciones legales o contractuales.

En sentido opuesto, señala el TJUE, si el propietario del caballo fuera retribuido por el organizador de la carrera por el mero hecho de su participación en la misma, siendo dicha retribución independiente de la clasificación finalmente obtenida, la puesta a disposición del caballo tendría la consideración de prestación de servicios a título oneroso y, por consiguiente, quedaría sujeta al IVA ${ }^{32}$. Esta conclusión resulta razonable si tomamos en consideración que, de haberse llegado a este tipo de acuerdo entre las partes, los propietarios que ponen su caballo a disposición del organizador de la carrera hípica tienen la absoluta certeza de que percibirán una retribución por hacerlo. De hecho, es muy probable que únicamente hayan accedido a participar en la carrera a cambio de recibir esta retribución ${ }^{33}$. Como resultado de ello, no solo desaparece el elemento de aleatoriedad o incertidumbre que caracteriza al premio como forma de retribución, sino que, además, no cabe duda de que, en este caso, la retribución percibida por el propietario del caballo constituye el contravalor efectivo del servicio prestado al organizador de la carrera. La concurrencia de ambos elementos pone de manifiesto la existencia de una relación directa entre el servicio prestado por el propietario del caballo y la retribución que le es satisfecha en concepto de contraprestación.

31 Sentencia Baštová, apdo. 36.

32 Esta circunstancia podría darse, tal y como señala el abogado general Nils Wahl en el punto 35 de sus conclusiones, «cuando un caballo es particularmente famoso y su simple participación en una carrera pueda incrementar el valor económico y el prestigio del evento. En esta situación, el pago realizado por el organizador de la carrera al propietario del caballo constituye una contraprestación por el servicio que este último le presta al aceptar prestar su caballo para que participe en la carrera».

33 En el mismo sentido se pronuncia el abogado general Nils Wahl en el punto 41 de sus conclusiones cuando señala que, "con carácter general, la posibilidad de ganar un premio suele constituir una de las motivaciones clave por las que los propietarios de caballos deciden inscribir a sus caballos en una carrera». 
En el hipotético supuesto de que, habiéndose pactado de antemano el pago de una retribución fija por la participación, el propietario del caballo aspirase también, en igualdad de condiciones con respecto al resto de participantes, a la obtención de un premio en función de los resultados alcanzados, el razonamiento del tribunal nos lleva a concluir que la base imponible del servicio prestado estaría formada, única y exclusivamente, por el importe de aquella contraprestación. En este sentido, señala el Tribunal de Justicia, «las conclusiones extraídas (...) carecen de incidencia sobre la cuestión, diferente, de la inclusión del premio que pueda eventualmente ganar el propietario del caballo, sujeto al IVA, en la base imponible, la cual depende de que este premio reciba la calificación de 'contrapartida de una prestación de servicios'». Dado que, en los términos señalados, «el premio que pueda ganar un caballo propiedad del sujeto pasivo no puede calificarse como contrapartida efectiva de la puesta a disposición del caballo por parte de su propietario a favor del organizador de una carrera hípica», concluimos que dicho premio no debe ser incluido bajo ningún concepto en la base imponible del IVA.

Como podemos comprobar, la decisión del TJUE en el asunto Baštová se hace depender finalmente de la ausencia de certeza en cuanto a la existencia misma de retribución, lo que supone una aproximación novedosa a la doctrina del vínculo directo. Aunque en su famosa sentencia Tolsma el Tribunal europeo ya efectuaba una somera referencia al componente de aleatoriedad inherente a la contraprestación recibida como criterio a tener en cuenta para descartar la sujeción al impuesto de una determinada transacción, lo cierto es que dicho criterio no jugó ningún papel determinante en el marco de aquel asunto; su utilidad se limitaba a reforzar una decisión previamente tomada ${ }^{34}$. Por esta razón, entendemos, no puede sostenerse que la sentencia Tolsma incorpore el elemento relativo a la certeza o ausencia de aleatoriedad en la contraprestación pactada a la doctrina del vínculo directo, aunque sí avanza la importancia que dicho elemento puede llegar a tener a la hora de apreciar la existencia de una relación directa entre la prestación de servicios cuya sujeción a IVA se discute y la contraprestación satisfecha por el destinatario de la misma. En nuestra opinión, es la sentencia Baštová la que verdaderamente introduce el requisito examinado a la doctrina del vínculo directo, ampliando a cinco, de este modo, el número de elementos a considerar para valorar la sujeción al IVA de una determinada prestación de servicios.

34 Esta sentencia es objeto de un examen más detallado en el epígrafe $\mathrm{V}$ del presente trabajo, donde se procede al análisis de la sentencia Baštová a la luz de la jurisprudencia comunitaria. 
Prueba de la afirmación anterior es que, en el marco del asunto Baštová, el Tribunal de Justicia niega la sujeción al IVA de la prestación hipotéticamente efectuada por el propietario del caballo ganador después de haber comprobado, y acreditado, la concurrencia de los cuatro elementos tradicionalmente ligados a la doctrina del vínculo directo. En este sentido, reconoce el TJUE la existencia de una relación jurídica, de carácter contractual y sinalagmático, entre el organizador de la carrera hípica y los propietarios de los caballos participantes; el carácter determinado y subjetivo de la contraprestación pactada, cuyo importe es fijo y conocido de antemano; y la existencia de un consumo y de un consumidor identificable (el organizador de la carrera hípica). Si bien los resultados del análisis acometido apuntan hacia la existencia de una relación directa entre prestación y contraprestación, el Tribunal europeo acaba resolviendo la inexistencia de tal relación directa, y, consecuentemente, la no sujeción al IVA de la prestación efectuada por el propietario del caballo ganador. El componente de aleatoriedad inherente a los premios como forma de retribución acaba operando, así, como criterio determinante de la decisión alcanzada por el Tribunal en este asunto, por lo que no cabe duda de que la sentencia Baštová implica una extensión del principio de "vínculo directo», cuyo cumplimiento se hará depender, a partir de este momento, de la concurrencia de cinco condiciones: a) la existencia de una relación jurídica de intercambio; b) y c) el carácter determinado y subjetivo de la contraprestación pactada; d) la existencia de un consumo y de un consumidor identificable, y e) el carácter cierto en cuanto a la existencia misma de retribución.

Además de reforzar el criterio de la certeza o ausencia de aleatoriedad, la sentencia Baštová supone otra aportación importante en este mismo contexto, al especificar o concretar el contenido del referido criterio. A este respecto conviene destacar que, si bien el requisito de certeza ya era objeto de mención expresa en la sentencia Tolsma, lo cierto es que en el marco de dicha sentencia el Tribunal de Justicia no ofrecía ningún criterio para valorar su cumplimiento. Esta indeterminación es suplida por el TJUE, al menos parcialmente, en la sentencia Baštová, donde expresamente se indica que el requisito de certeza en cuanto a la existencia misma de retribución no se cumple en aquellos casos en los que la contraprestación pactada entre las partes se materialice en el pago de un premio. Tal incumplimiento determina la ruptura del vínculo directo que necesariamente debe existir entre prestación y contraprestación y, por ende, la no sujeción al IVA de la transacción realizada por el perceptor del premio ${ }^{35}$.

35 En este mismo sentido, véase LANG et al., op. cit., nota 11, p. 242. 


\section{CONEXIÓN DE LA SENTENCIA BAŠTOVÁ CON EL DERECHO ESPAÑOL}

\section{LA DOCTRINA DE LA DIRECCIÓN GENERAL DE TRIBUTOS (DGT)}

La sentencia Baštová reviste una importancia notable en el ámbito del ordenamiento jurídico español, cuya Administración tributaria se ha pronunciado en reiteradas ocasiones a favor de la sujeción al IVA de los premios obtenidos en una competición deportiva ${ }^{36}$. Un claro exponente del criterio seguido por la DGT en este ámbito viene representado por la consulta V0642-12, de 27 de marzo, en la que dicho órgano sostiene que «las prestaciones de servicio (...) consistentes en la participación en carreras de caballos por la propietaria de los mismos conlleva la realización de una actividad empresarial o profesional, cualquiera que sea la modalidad de la contraprestación que perciba con ocasión de los mismos (cantidad fija por participación, premios o pagos en metálico en función de la clasificación obtenida u otras), estando sus operaciones sujetas y no exentas al Impuesto sobre el Valor Añadido" ${ }^{37}$. Idéntico criterio se reproduce, asimismo, en las consultas 1961-99, de 22 de octubre, y 0203-01, de 6 de febrero, en las que también se analiza la tributación en el IVA de los premios satisfechos a los empresarios y profesionales que participan en carreras de caballos.

Una revisión de las principales resoluciones emitidas en torno a esta materia parece poner de manifiesto que la sujeción al IVA de los premios no es una cuestión generadora de dudas para la Administración tributaria española, ya que es susceptible de ser resuelta directamente mediante la aplicación de los arts. 4 y 5 de la Ley 37/1992, de 28 de diciembre, del Impuesto sobre el Valor Añadido (LIVA). Concretamente, establece el artículo 4. Uno LIVA que

36 Además de haber analizado la tributación en el IVA de los premios derivados de la participación en competiciones deportivas, la DGT se ha pronunciado en algunas ocasiones sobre el tratamiento que deben recibir los premios obtenidos por razones distintas a esta. A título de ejemplo, la consulta V2330-14, de 9 de septiembre, alude, entre otros aspectos, al tratamiento que deben recibir, en el ámbito del IVA, los premios percibidos por una sociedad limitada compuesta por médicos dermatólogos. La consulta V1422-12, de 29 de junio, por su parte, se pronuncia a favor de la sujeción al impuesto de los premios recibidos en el marco de un concurso gastronómico en el que participan bares y restaurantes de la ciudad previamente inscritos.

37 Del mismo modo, prosigue la DGT en la consulta citada, «tiene la consideración de prestación de servicios sujeta al Impuesto la participación de los yoqueis profesionales en las carreras de caballos, teniendo la consideración de contraprestación los premios que pudieran obtener como consecuencia de la mencionada participación». 
«Estarán sujetas al impuesto las entregas de bienes y prestaciones de servicios realizadas en el ámbito espacial del impuesto por empresarios o profesionales a título oneroso, con carácter habitual u ocasional, en el desarrollo de su actividad empresarial o profesional, (...)». Por su parte, dispone el artículo 5. Uno que, a los efectos de este impuesto, se considerarán empresarios o profesionales, entre otros: «a) Las personas o entidades que realicen las actividades empresariales o profesionales definidas en el apartado siguiente de este artículo» $\mathrm{y}$ «b) Las sociedades mercantiles, salvo prueba en contrario.» Finalmente, señala el artículo 5. Dos LIVA que «Son actividades empresariales o profesionales las que impliquen la ordenación por cuenta propia de factores de producción materiales y humanos o de uno de ellos, con la finalidad de intervenir en la producción o distribución de bienes o servicios. En particular, tienen esta consideración las actividades extractivas, de fabricación, comercio y prestación de servicios, incluidas (...) el ejercicio de profesiones liberales y artísticas».

Frente a las dudas que la cuestión planteada parece suscitar en el marco de la sentencia Baštová, el elemento verdaderamente relevante para determinar la tributación en el IVA del premio recibido por el participante en una carrera hípica no radica, a juicio de la DGT, en el carácter oneroso de la prestación de servicios realizada por este, sino en la existencia de una relación directa entre el premio que se recibe y la actividad económica desarrollada por el ganador, lo que, a su vez, exige la concurrencia de dos requisitos. Por un lado, que el ganador del premio sea empresario o profesional, y, por otro, que dicho premio sea obtenido en el marco de su actividad empresarial o profesional. Estos criterios están presentes en las consultas 0203-01, de 6 de febrero; V1026-09, de 8 de mayo; V0642-12, de 27 de marzo; y V3438-16, de 20 de julio.

A título de ejemplo, establece la consulta V1026-09, referida a una sociedad limitada que se dedica a la organización de campeonatos de golf para profesionales, que, «en la medida en que los referidos premios en metálico van a ser percibidos por jugadores profesionales de golf constituirán la contraprestación de su actividad profesional. Esto es, supondrán la contraprestación de una prestación de servicios sujeta al Impuesto efectuada por el jugador profesional, que tendrá la condición de empresario o profesional, a tenor de lo establecido en los artículos 4 y 5 de la Ley 37/1992, (...) efectuada en el ejercicio de su actividad». En la misma línea, concluye la DGT en la reciente consulta V3438-16 que «los pilotos profesionales que participan en las carreras prestando servicios sujetos y no exentos a los organizadores de dichos eventos están obligados a expedir y entregar la correspondiente factura en la que se repercuta el Impuesto sobre el Valor Añadido por los premios recibidos».

De acuerdo con la doctrina administrativa española, la sujeción al IVA del servicio prestado al organizador del evento por el deportista que participa 
en él (en nuestro caso particular, el propietario del caballo) vendría justificada por la concurrencia de todos los elementos necesarios para que se entienda realizado el hecho imponible; entre ellos, por tratarse de una prestación de servicios realizada por un empresario o profesional en el desarrollo de su actividad. Por lo que respecta al carácter oneroso de la prestación, del contenido de las consultas mencionadas se desprende que, a diferencia de lo que sucede en el marco comunitario, la DGT no cuestiona en ningún momento el cumplimiento de este requisito. Así pues, tal y como se señala en diversas consultas, el carácter oneroso del servicio prestado por el participante en la competición estaría vinculada a la posibilidad de recibir "premios o pagos en metálico en función de la clasificación obtenida ${ }^{38}$.

\section{LA DOCTRINA DE LOS TRIBUNALES ESPAÑOLES}

En línea con la tesis sostenida por la DGT, el Tribunal Económico-Administrativo Central (TEAC), la Audiencia Nacional (AN) y algunos tribunales superiores de justicia (TSJ) han defendido que la participación en carreras de caballos se configura como una actividad económica a la luz del derecho comunitario y que los premios eventualmente percibidos en función de la clasificación obtenida tienen naturaleza de contraprestación por el servicio prestado al organizador del evento. En consecuencia, la puesta a disposición de un caballo para su participación en una carrera hípica constituye una prestación de servicios sujeta y no exenta del IVA, debiendo su propietario repercutir el impuesto al organizador de la misma sobre el importe de la retribución fija que se haya pactado, el importe del premio percibido (en caso de que no se haya fijado una remuneración por la participación y el propietario resulte perceptor de un premio) o, en su caso, sobre ambos importes.

Desde el punto de vista de su posible consideración como actividad económica (o, cuando menos, como parte de la misma) la resolución del TSJ de Andalucía (Sala de lo Contencioso), sentencia 2722/2012, de 5 de noviembre de 2012, se centra en dilucidar si la actividad desarrollada por el recurrente, consistente en la cría, doma y venta de caballos, así como en la participación en carreras para ganar premios, constituye una actividad empresarial a efectos del IVA. A este respecto, señala el referido órgano, en la medida en que dicha actividad «no está orientada sólo a la obtención de premios sino, también, a la ordenación de los recursos pertinentes a su consecución, como la cría y doma

38 Así se desprende, entre otras, del contenido de las consultas 1961-99, 0203-01, V1026-09 y V0642-12, donde la DGT se refiere al premio eventualmente recIbido por el participante como contraprestación por el servicio prestado al organizador. 
de los animales, así como a la venta de los mismos», «quedan demostradas dos de las exigencias legales para la actividad económica, una la ordenación por cuenta propia de factores productivos y, por otro, la finalidad de intervenir en la producción o distribución de bienes y servicios».

Por lo que se refiere a la posibilidad de atribuir al premio percibido naturaleza de contraprestación por el servicio prestado, señala el TEAC en su resolución de 8 de marzo de 1995 que «es claro que la actividad de la reclamante consiste en una prestación de servicios, consistente en participar de modo habitual en la celebración de carreras de caballos (...) a cambio de una contraprestación ya sea fija o con carácter aleatorio en el caso de obtención de premios en función del puesto de llegada " ${ }^{39}$. En el mismo sentido, dispone la AN (Sala de lo Contencioso), sentencia 1763/1998, recurso 305/1995, de 8 de junio de 1998, acerca de la actividad consistente en la cría de caballos para su explotación mediante la participación en carreras hípicas, que «el que se hace acreedor a un premio recibe una contraprestación por la prestación del servicio, lo que, a los efectos del Impuesto, le diferencia sustancialmente del otro participante que no recibe nada. En todo caso, (...) la actividad de la actora consiste en participar en carreras de caballos a cambio de una contraprestación. Esta, en ocasiones es fija, y se le abona una suma únicamente por competir, y en ocasiones es aleatoria, y se le abona al ganador o al que logra colocarse en determinada posición. La actividad en consecuencia está sujeta».

Como vemos, el razonamiento esgrimido por el tribunal en los tres casos indicados coincide con el de la DGT en un aspecto fundamental, como es la aceptación del carácter oneroso de la operación cuando la contraprestación recibida a cambio se materializa en un premio. Tanto la DGT como los tribunales españoles se muestran conformes con el hecho de que el premio percibido por el participante en una carrera hípica se configura como la contraprestación por el servicio prestado al organizador del evento. Esta identidad de criterio no se observa, sin embargo, en relación con otros aspectos de la cuestión debatida. Por ejemplo, mientras la DGT centra su atención en analizar si el sujeto pasivo que participa en una competición deportiva realmente está actuando en el marco de su actividad empresarial o profesional cuando lo hace, el TEAC, el TSJ de Andalucía y la AN se muestran algo más dispersos.

Concretamente, lo que parece presentarse como elemento nuclear del caso para el TSJ de Andalucía es la posibilidad de concebir al propietario del caballo como empresario o profesional a efectos del IVA, lo que a su vez dependerá de que dicho individuo desarrolle una actividad económica con

39 Resolución del TEAC de 8 de marzo de 1995, ref. 3601/1995. 
carácter habitual. La AN, por su parte, centra su atención en la posibilidad de considerar el premio eventualmente recibido por el propietario del caballo como contraprestación por el servicio prestado, y, por ende, en el carácter oneroso o no oneroso de la operación.

Por las mismas razones esgrimidas en el epígrafe anterior de este trabajo, opino que los tribunales españoles fallan al atribuir carácter oneroso a la prestación de servicios efectuada por el propietario del caballo. Por lo que respecta a la tesis de la $\mathrm{AN}$, es cierto que dicho órgano acierta al identificar el carácter oneroso o no oneroso de la operación realizada como eje central del caso. No obstante, considero que su razonamiento pone de manifiesto una cierta imprecisión terminológica. Así, tal y como se desprende de la directiva comunitaria en materia de IVA, lo que queda sujeto al impuesto cuando concurren las condiciones necesarias para ello no es la actividad empresarial o profesional desarrollada por el sujeto pasivo, sino la específica operación de entrega de bienes o prestación de servicios que el mismo realiza en el marco de esta actividad.

\section{ANÁLISIS DE LA SENTENCIA BAŠTOVÁ A LA LUZ DE LA JURISPRUDENCIA COMUNITARIA}

La decisión del Tribunal de Justicia en la sentencia Baštová echa por tierra el criterio tradicionalmente sostenido por la Administración tributaria y por los tribunales españoles en lo que atañe a la sujeción al IVA de los premios obtenidos en el marco de una competición deportiva o evento similar. Mientras estos últimos consideran que una prestación de servicios cuya retribución se materializa en un premio constituye una operación sujeta y no exenta, aquel se decanta por defender la no sujeción al impuesto al no apreciar la existencia de una relación directa entre el servicio prestado y la retribución obtenida.

A priori, la existencia de tal disparidad de criterios nos lleva a concluir que, en las últimas décadas, la doctrina administrativa y jurisprudencial española se ha apartado sistemáticamente de la jurisprudencia comunitaria en relación con los elementos que debe reunir una prestación de servicios para considerarse efectuada a título oneroso. Del estudio de los argumentos esgrimidos en cada caso parece desprenderse, sin embargo, que estas divergencias de opinión vienen justificadas por una incorrecta interpretación de los criterios que deben regir la aplicación del derecho comunitario, lo cual puede resultar comprensible si tenemos en cuenta que la sentencia Baštová es la primera en la que se aborda directamente el tema de la sujeción al IVA de los premios derivados de la participación en una competición deportiva. 
Una de las sentencias más relevantes del TJUE acerca de los requisitos que debe reunir la contraprestación recibida por el sujeto pasivo para que una prestación de servicios se encuentre sujeta al IVA fue la dictada el 3 de marzo de 1994 en el conocido asunto Tolsma, antes citado, a la que tanto el abogado general en sus conclusiones como el propio Tribunal de Justicia a lo largo de la sentencia Baštová aluden en diversas ocasiones ${ }^{40}$. En concreto, esta sentencia analiza la sujeción al impuesto, en concepto de prestación de servicios a título oneroso, de la actividad consistente en la interpretación de música en la vía pública por un individuo que, no habiendo pactado remuneración alguna con los destinatarios del servicio, pide dinero a los viandantes y recibe donativos. En un contexto como este, entiende el Tribunal, la prestación de servicios realizada no quedará sujeta al IVA, ya que no se acredita la existencia de una relación directa entre el servicio que se presta y la contraprestación que se recibe a cambio. En primer lugar, porque «no existe ningún pacto entre las partes, puesto que los viandantes entregan voluntariamente un donativo cuyo importe determinan ellos mismos libremente»; en segunda instancia, porque «no existe ningún vínculo necesario entre la prestación musical y las entregas de dinero a que da lugar» ${ }^{41}$. Asimismo, se añade, «No puede enervar esta interpretación el hecho de que un músico (...) pida dinero y pueda esperar, de hecho, recibir determinada cantidad interpretando música en la vía pública. En efecto, estos pagos son meramente voluntarios y aleatorios y su cuantía es prácticamente imposible de determinar $»^{42}$.

En consonancia con el razonamiento esgrimido en la sentencia Tolsma, la existencia de un convenio o pacto entre las partes con respecto a la remuneración que debe satisfacerse como contraprestación por el servicio recibido contribuye a poner de manifiesto una cierta relación entre ambos elementos. Esto es lo que sucede en aquellos casos en los que el organizador de una competición deportiva se obliga al pago de una cantidad en concepto de premios a los participantes que obtengan una determinada clasificación al llegar a la meta, de modo que tanto el número como el importe de los premios, así como las condiciones en que se concederán, «están establecidos con carácter previo y son conocidos por los propietarios que, al inscribir un caballo en la carrera, los aceptan ${ }^{43}$. La consideración aislada de esta circunstancia en el ámbito en el que nos encontramos podría sustentar la tesis de que el premio percibido por

\footnotetext{
40 Véase sentencia Baštová, apdos. 28 y 29, y conclusiones del abogado general Nils Wahl, punto 42 .

41 Sentencia Tolsma, antes citada, apdo. 17.

42 Sentencia Tolsma, apdo. 19.

43 Conclusiones del abogado general Nils Wahl, punto 41.
} 
los participantes cuyos caballos obtengan un mejor rendimiento en la carrera se encuentra sujeto al impuesto, puesto que parece haber certeza en cuanto a la existencia de la remuneración y en cuanto a su importe.

No obstante lo anterior, del contenido de la sentencia Tolsma se desprende también que la existencia de una relación jurídica entre el prestador del servicio y su destinatario, en cuyo marco se intercambian prestaciones recíprocas, es una condición necesaria pero no suficiente para que una prestación de servicios se entienda realizada a título oneroso. Para acreditar este requisito es necesario, asimismo, que la retribución percibida por quien efectúa la prestación constituya el contravalor efectivo del servicio prestado al destinatario. En relación con este segundo elemento, no cabe duda de que, cuando el organizador de una carrera de caballos se compromete al pago de una cuantía determinada en concepto de premios, el pago del premio no reviste carácter voluntario sino obligatorio para él. Además, en los términos antes indicados, lo más habitual es que tanto el importe como las condiciones de pago de los premios se encuentren fijados de antemano y sean conocidos por las partes. Sin embargo, como señala el TJUE en el apdo. 37 de la sentencia Baštová, «no es la puesta a disposición del caballo por parte de su propietario a favor del organizador de la carrera hípica la que, como tal, da derecho al pago de un premio, sino la obtención de un determinado resultado a la finalización de la carrera, esto es, la clasificación del caballo en un puesto determinado", de tal suerte que la obtención del premio "queda supeditada a un rendimiento determinado y sujeto en cierta medida al azar». Este componente de aleatoriedad e incertidumbre en cuanto a la existencia misma de una retribución excluye «la existencia de un vínculo directo entre la puesta a disposición del caballo y la obtención de un premio» ${ }^{44}$.

De acuerdo con lo expuesto, un análisis de la problemática descrita a la luz de los argumentos empleados por el Tribunal de Justicia en la sentencia Tolsma contribuye igualmente a fundamentar la tesis de que el premio percibido por el participante en una carrera hípica no tiene naturaleza de contraprestación por el servicio prestado al organizador de la misma, y, por ende, que dicho servicio no se encuentra sujeto al IVA. Así, dado que el carácter aleatorio de la contraprestación pactada rompe el vínculo necesario entre la prestación del servicio que realiza el propietario del caballo y el pago que eventualmente recibe del organizador del evento, dicha operación caerá fuera del ámbito de aplicación del citado impuesto.

Efectuando una confrontación entre el razonamiento del TJUE y el razonamiento del abogado general en el asunto Baštová (que también se posiciona

44 Sentencia Baštová, apdo. 38. 
a favor de una tesis contraria a la del Tribunal de Justicia), llama la atención el hecho de que, en opinión de este último, el servicio prestado al organizador de la carrera no consiste en la puesta a disposición del caballo para su participación en la misma, sino en el rendimiento sobresaliente del caballo en la carrera. De esta forma, el premio recibido constituiría una contraprestación por la habilidad y buen rendimiento del caballo, «que ha enriquecido el evento al hacerlo más interesante y valioso» ${ }^{45}$.

A mi juicio, el abogado general Nils Wahl se equivoca al establecer una correlación entre el rendimiento del caballo en la carrera y el premio obtenido por su propietario, ya que dicha conclusión parte de una confusión entre la verdadera prestación de servicios que el propietario del caballo realiza con la condición que necesariamente debe darse para que dicho individuo se convierta en acreedor del premio.

Esta misma cuestión es analizada por Lang et al., quienes sostienen que el hecho de que uno o más caballos destaquen por un excelente rendimiento es parte del juego ${ }^{46}$. Puede ser verdad, admiten los autores, que el organizador del evento se comprometa a entregar el premio al propietario del caballo ganador, pero dicho "pago» no está directamente relacionado con el beneficio real que tal individuo espera recibir de cada uno de los propietarios participantes (incluido el propietario del caballo ganador). Dado que los propietarios de los caballos no ganadores no reciben ninguna contraprestación por su parti-

45 Concretamente, señala el abogado general, cuando el propietario del caballo pone el animal a disposición del organizador de la carrera le permite "poner en marcha un evento al que es posible que asista público, que puede que retransmitan los medios de comunicación y que puede ser interesante para patrocinadores y anunciantes. El organizador de la carrera no podría organizar y publicitar su evento si no participan en él un cierto número de caballos y (...) cuanto mayores sean las habilidades de los caballos, mayor será el valor comercial del evento. Por lo tanto, (...) tanto el organizador de la carrera como el propietario del caballo perciben un beneficio directo e individual de la operación. En consecuencia, existe una relación directa entre el rendimiento sobresaliente de un caballo en una carrera (servicio prestado) y el pago del premio (contraprestación recibida)». En un sentido similar, afirmaba el TJUE en el apdo. 57 de la Sentencia Deliège, C-51/96, EU:C:2000:199, acerca de la organización y participación en una competición internacional de alto nivel, que «el organizador de tal competición ofrece al deportista la posibilidad de realizar su actividad deportiva compitiendo con otros contendientes y, correlativamente, mediante su participación en la competición, los deportistas permiten que el organizador ofrezca un espectáculo deportivo al que puede asistir el público, que puede ser retransmitido en televisión y que puede interesar a los anunciantes publicitarios y a los patrocinadores».

LANG et al., op. cit., nota 11, p. 246. 
cipación en la carrera, las supuestas prestaciones de servicio que los mismos efectúan no serán sometidas a imposición en ningún caso. Así las cosas, parece claro que el propietario del caballo no recibe el premio por realizar la misma prestación de servicios que el resto de participantes, sino únicamente por el rendimiento sobresaliente de su caballo en la carrera. Debe tenerse en cuenta, no obstante, que lo que realmente pretende el organizador del evento no es que uno de los participantes en la competición demuestre un rendimiento sobresaliente y superior a la del resto, sino atraer individuos altamente cualificados y motivados. Aunque se asuma que uno de los participantes ganará la carrera, el verdadero interés del organizador del evento no recae sobre el resultado del evento, sino sobre el evento en sí.

Por otro lado, considero que el elemento clave en el asunto analizado no radica en determinar si el propietario del caballo efectúa una prestación de servicios a favor del organizador de la carrera, ni en qué consiste dicho servicio, pues ambos extremos son admitidos por el TJUE sin más dilaciones. De lo que se trata es de esclarecer si el premio entregado por el organizador se configura como remuneración de dicha prestación de servicios. Solo en tal caso podría entenderse que efectivamente existe una relación directa entre el servicio prestado y la contraprestación recibida a cambio, y, en consecuencia, que dicho servicio se encuentra sujeto al IVA.

El carácter oneroso, o no oneroso, de la prestación de servicios que realiza el propietario de un caballo cuando pone su animal a disposición del organizador de una carrera hípica se configura, de hecho, como principal elemento conflictivo en el plano doctrinal. Mientras el Tribunal de Justicia defiende que el premio eventualmente percibido no constituye una contrapartida efectiva por el servicio prestado, tanto la DGT como los tribunales españoles que han abogado por la sujeción al IVA de la operación parten de la premisa contraria $^{47}$.

En un sentido similar, autores como Pfeiffer y Ursprung-Steindl han sostenido que los premios y trofeos derivados de la participación en una competición deportiva pueden ser considerados como contraprestación de una prestación de servicios, ya que el principal objetivo del participante consiste, precisamente, en ganar la competición para recibir un premio o para conseguir una mejor reputación. Sin embargo, destacan los autores la necesidad

47 Sobre la base de las resoluciones emitidas por la DGT, sustentan Luis Ma CAZORLA PRIETO y Amable CORCUERA TORRES la sujeción al IVA de las prestaciones de servicios consistentes en la participación en eventos y competiciones deportivas, «cualquiera que sea la modalidad de contraprestación que perciba con ocasión de las mismas» (Los impuestos del deporte, Aranzadi, Navarra, 1999, p. 273). 
de efectuar una distinción entre esta situación y aquella otra en la que un determinado individuo recibe un premio o trofeo, no con ocasión de su participación en un evento específico, sino como reconocimiento a su reputación y sobresaliente carrera, que en ningún caso quedará sujeto al IVA ${ }^{48}$. De conformidad con esta tesis, por tanto, el elemento determinante de la existencia o no de vínculo directo entre la prestación realizada y el premio percibido, entendido como contraprestación de dicha prestación, radicaría en la intencionalidad del individuo premiado. Así, solo cuando el premio fuese concedido como reconocimiento al excelente resultado obtenido en el marco de un evento específico (en el que, de hecho, el individuo participa con la intención de ganar) podría apreciarse sujeción al impuesto.

\section{LA TESIS DEL ABOGADO GENERAL EN EL ASUNTO BAŠTOVÁ. COMENTARIO CRÍTICO}

En los términos antes comentados, la opinión esgrimida por el TJUE en la sentencia Baštová choca frontalmente con la tesis defendida en el marco de este mismo asunto por el abogado general Nils Wahl, para quien la propia jurisprudencia comunitaria justifica la conclusión de que «el premio en efectivo obtenido en una carrera de caballos debe estar sujeto a IVA». En primer lugar, porque la puesta a disposición de un caballo por parte de su propietario a favor del organizador de la carrera con la intención de obtener un ingreso derivado del premio que eventualmente se obtenga se efectúa en el marco de una actividad empresarial. En segunda instancia, porque el premio obtenido tiene naturaleza de contraprestación de una prestación de servicios y el hecho de que su pago "esté supeditado al cumplimiento de una condición concreta no priva a la operación de su carácter oneroso».

Centrándonos en los argumentos esgrimidos para justificar su conclusión, el señor Nils Wahl alude, por un lado, al criterio mantenido por el Tribunal de Justicia en su Sentencia Hong-Kong Trade, C-89/81, EU:C:1982:121, apdo. 11, conforme al cual «El carácter oneroso de las operaciones imponibles se confirma por el hecho de que las actividades económicas de los sujetos pasivos (...) son necesariamente actividades ejercidas con el fin de obtener un contravalor o que pueden retribuirse mediante un contravalor (...)». En efecto, el TJUE ha señalado en numerosas ocasiones que para que una prestación de servicios se encuentre sujeta al IVA es necesario que exista una contra-

48 Sebastian PFEIFFER y Marlies URSPRUNG-STEINDL, Global Trends in VAT/GST and Direct Taxes, Linde Verlag, 2015, pp. 540-541. 
prestación por medio de la cual se retribuya el servicio prestado por el sujeto pasivo. A mi entender, sin embargo, la aplicación de esta jurisprudencia al caso concreto no puede realizarse de forma aislada, olvidando el resto de requisitos que, a la luz del derecho comunitario, debe reunir la remuneración pactada entre el proveedor del servicio y su destinatario para que la operación se entienda efectuada a título oneroso. En este sentido, es jurisprudencia del Tribunal de Justicia que el carácter incierto en cuanto a la existencia misma de la retribución rompe el vínculo que necesariamente debe existir entre el servicio que se presta y la contraprestación que por ello se recibe.

Ciertamente, cuando el propietario de un caballo de carreras participa en una competición deportiva lo hace con el fin de obtener un beneficio o contravalor. Dicho contravalor puede consistir en la percepción de un premio o, como señala el propio Tribunal en la sentencia Baštová, en el beneficio «derivado del aumento del valor del caballo en atención a su clasificación o a la publicidad que le confiere esta participación ${ }^{49}$. Tanto en uno como en otro caso, no obstante, la existencia del referido contravalor resulta incierta, ya que depende de una circunstancia aleatoria como es el resultado de la carrera, y, en definitiva, del $\operatorname{azar}^{50}$. Así pues, se trata de una situación similar a la planteada en la sentencia Tolsma, donde el TJUE niega la existencia de una relación directa entre el servicio prestado y los pagos percibidos por el proveedor de dicho servicio como consecuencia de su carácter aleatorio y la práctica imposibilidad de determinar su cuantía.

En segunda instancia, el abogado general hace referencia a la Sentencia del Tribunal de Justicia Saudaçor, C-174/14, EU:C:2015:733, apdo. 37, donde se admite la existencia de un vínculo directo entre prestación del servicio y contraprestación recibida a pesar del carácter incierto de su cuantía. Concretamente, la sentencia Saudaçor describe el caso de una entidad dedicada a la prestación de servicios en materia de planificación y gestión del Servicio Regional de Salud que suscribe una serie de contratos de prestación de servicios con la Región de las Azores. En tales contratos se determina, a tanto alzado y sobre la base de unos criterios establecidos, el importe de la compensación anual que debe ser abonada por la recepción de tales servicios, al tiempo que se incluye una cláusula de revisión que tiene por objeto «adaptar el importe de la contrapartida a tanto alzado a las prestaciones suministradas de manera continua y permanente». En este contexto, la cuestión que se plantea al TJUE

49 Sentencia Baštová, apdo. 35.

50 En el segundo caso, además, debemos tener en cuenta que la contraprestación recibida por el propietario del caballo no es satisfecha por el organizador de la competición en su calidad de destinatario del servicio. 
radica en la posibilidad de establecer un vínculo directo entre el servicio prestado por el sujeto pasivo y la contraprestación recibida a cambio cuando el importe de dicha contraprestación es fija y conocida de antemano, pero susceptible de modificación o ajuste posterior. La respuesta dada por el Tribunal en el apdo. 37 de la sentencia es que no "parece poder cuestionarse la existencia de dicho vínculo por el hecho de que los contratos programa celebrados (...) incluyan determinadas cláusulas que estipulan que el importe de la compensación (...) podrá ajustarse cuando, debido a un cambio de circunstancia, dicho importe resulte manifiestamente insuficiente».

En lo que atañe a las implicaciones que la sentencia Saudaçor está llamada a tener en el ámbito en el que ahora nos encontramos, conviene tener en cuenta que el problema analizado en dicha sentencia difiere sustancialmente del descrito en el asunto Baštová. A mi parecer, de hecho, la magnitud de las diferencias existentes entre ambos supuestos veda toda posibilidad de acudir a los criterios interpretativos defendidos por el TJUE en la sentencia Saudaçor para fundamentar la sujeción o no sujeción al IVA de los premios obtenidos en una competición deportiva. Así, lo que plantea dudas en el asunto Saudaçor no es la existencia de una contraprestación por los servicios que presta el sujeto pasivo, sino la posibilidad de que la cuantía de dicha contraprestación sea objeto de modificación posterior en función de las circunstancias concurrentes. Tal sería el caso si, en el marco de una carrera de caballos, el organizador del evento se comprometiese a pagar un importe en metálico a todos los participantes, pero la determinación de dicho importe se realizase ex post en función de la clasificación del caballo al llegar a la meta. Sin embargo, esto no es lo que sucede en el asunto Baštová, donde, si bien es cierto que el importe del premio se encuentra fijado de antemano y es conocido por las partes, ninguno de los participantes en la carrera tiene garantizada su percepción.

Desde mi punto de vista, un estudio detallado de la cuestión debatida en la sentencia Baštová nos lleva a rechazar, en línea con la conclusión esgrimida por el Tribunal de Justicia, la sujeción al impuesto del servicio prestado por el propietario del caballo al organizador de la carrera hípica. Esta tesis es la que naturalmente deriva de una aplicación estricta al caso de la jurisprudencia consolidada del TJUE con relación a los requisitos que necesariamente deben concurrir para que una prestación de servicios se entienda realizada a título oneroso y, por ende, caiga dentro del ámbito de aplicación del IVA. Por el contrario, no creo que la jurisprudencia citada por el abogado general Nils Wahl en sus conclusiones permita fundamentar la tesis opuesta. En primer lugar, porque las sentencias del Tribunal de Justicia no pueden ser interpretadas nunca aisladamente, sino que deben ser analizadas en el marco de la línea jurisprudencial más amplia en la que se insertan. En segunda instancia, porque considero que los argumentos defendidos por el TJUE en una sen- 
tencia anterior únicamente pueden hacerse valer como fundamento de una conclusión cuando exista una identidad fáctica, o cuando menos una notable similitud, entre el supuesto de hecho que se trae a colación y aquél que se pretende resolver.

\section{CONCLUSIONES}

A la hora de determinar la sujeción al IVA del servicio consistente en la puesta a disposición de un caballo para su participación en una carrera hípica, el TJUE distingue dos supuestos claramente diferenciados. Por un lado, cuando el organizador del evento no paga ninguna cantidad al propietario del caballo en concepto de remuneración por su participación en la carrera, de modo que solo aquellos propietarios cuyos caballos obtengan ciertas clasificaciones reciban un premio, la puesta a disposición del caballo no constituye una operación sujeta al impuesto. Este resultado no se ve afectado por el hecho de que el organizador del evento se encuentre obligado al pago del premio y la cuantía del mismo sea fija y conocida de antemano. Por el contrario, si el propietario del caballo percibiese una retribución del organizador por su mera participación en la carrera, siendo dicha retribución independiente de la clasificación obtenida, la puesta a disposición del caballo daría lugar a una operación sujeta al IVA.

Mediante la defensa de esta tesis, el Tribunal de Justicia ha venido a echar por tierra el criterio tradicionalmente sostenido por la DGT, y, en línea con esta, por el TEAC, la AN y algunos TSJ, para quienes la participación de un empresario o profesional en una carrera de caballos mediante contraprestación, ya se trate de un importe fijo previamente pactado o de cualquier otra clase de remuneración condicionada a la obtención de una determinada clasificación en la carrera (por ejemplo, un premio), constituye una prestación de servicios a título oneroso, sujeta y no exenta del impuesto.

La conclusión defendida por el Tribunal en la sentencia Baštová se muestra plenamente coherente con la llamada doctrina del vínculo directo, centrada en la necesaria existencia de una relación directa entre la prestación que se realiza y la contrapartida que se recibe a cambio, de tal suerte que no nos encontramos ante un cambio de criterio por parte de este órgano jurisdiccional. Dicha circunstancia no impide afirmar, sin embargo, que la sentencia Baštová supone una extensión del principio de vínculo directo, y, consecuentemente, un notable avance en el proceso de formulación de la referida doctrina, ya que determina la incorporación a la misma de un nuevo elemento: la certeza en cuanto a la existencia de retribución, un criterio que ya apuntaba el Tribunal europeo en la sentencia Tolsma pero que, a diferencia de lo ahora sucedido, en 
modo alguno resultó determinante para negar la sujeción al IVA de las prestaciones musicales controvertidas. De aquí la notable relevancia que la sentencia Baštová está llamada a tener en el ámbito en el que nos encontramos, máxime teniendo en cuenta que, además de lo acaecido en el caso español, otros Estados miembros de la Unión Europea han venido defendiendo la sujeción al IVA de los premios derivados de la participación en toda clase de competiciones (deportivas, culturales, empresariales, etc. $)^{51}$.

En lo que concierne al ordenamiento interno, la principal conclusión a la que llegamos tras un análisis de las consultas, resoluciones y sentencias más relevantes es que la doctrina administrativa y jurisprudencial española choca frontalmente con el pronunciamiento del alto tribunal europeo en la sentencia Baštová. La necesaria adaptación a los criterios interpretativos del derecho comunitario expuestos por el TJUE, sin embargo, hace esperar que, en futuros pronunciamientos, tanto la DGT como los tribunales españoles se decanten por resolver la no sujeción al IVA de aquellas prestaciones de servicios cuya retribución se materialice en un premio. Entre ellas, las asociadas a la participación en una competición deportiva o en un evento de similar naturaleza.

51 En Alemania, por ejemplo, los premios concedidos por un panel de expertos con ocasión de un logro individual se consideran sujetos al IVA. En este sentido se ha pronunciado la Corte Fiscal de Münster al concluir que el premio percibido por un determinado distrito o barrio a raíz de su participación en una competición empresarial tiene naturaleza de contraprestación por una prestación de servicios (KPMG, Hot topics and issues in indirect taxation, VAT Newsletter, December 2016, p. 2). 